This is a post-peer-review, pre-copyedit version of an article published in International Journal of Sustainable Transportation. The final authenticated version is available online at:

https://doi.org/10.1080/15568318.2020.1847367

To cite this article:

Chiara Siragusa, Angela Tumino, Riccardo Mangiaracina \& Alessandro Perego (2020) Electric vehicles performing last-mile delivery in B2C e-commerce: An economic and environmental assessment, International Journal of Sustainable Transportation, DOI: 10.1080/15568318.2020.1847367

\title{
Electric vehicles performing last mile delivery in B2C e-commerce: An economic and environmental assessment
}

\author{
International Journal of Sustainable Transportation \\ Siragusa Chiara, Mangiaracina Riccardo, Perego Alessandro, Tumino Angela \\ Department of Management, Economics and Industrial Engineering, Politecnico di Milano \\ 4B Lambruscbini street, 20156 - Milano - Italy
}

\begin{abstract}
The proliferation of e-commerce in the recent years has been recognized to have a huge impact on transportation owing to the increasing need for last mile deliveries in urban areas. Further, it is claimed to be responsible for the rising number of vans moving in cities, considerably impacting environmental sustainability. In this context, electric vehicles (EVs) could substitute internal combustion engine vehicles (ICEVs) to mitigate their harmful impact on the environment. The present work aims to provide a comparison between the EVs and the ICEVs used to perform last mile deliveries in business-to-consumers (B2C) e-commerce, considering both economic and environmental perspectives. The life cycle assessment method is adopted for the evaluation of environmental impact. However, economic assessment is based on the total cost of ownership analysis, which allows the comparison between the two types of vehicles throughout the ownership period. The analysis was conducted considering an Italian city (Milan). The use of EVs proved to be economically beneficial when an 8-year timeframe was considered. Even if the initial investment for EVs is high, owing to a purchasing price that is nearly double when compared to ICEVs, the lower operating expenditure makes EVs a competitive option. Considering the environmental perspective, EVs turned out to be the best option in all the scenarios assumed. In particular, EVs lead to a decrease in greenhouse gas (GHG) emissions by $17 \%$ (in the $20 \mathrm{~km} /$ day case) to by $54 \%$ (in the $120 \mathrm{~km} /$ day case), or even more if a higher daily mileage is considered.
\end{abstract}

Keywords: B2C e-commerce; electric vehicle; environmental sustainability; last mile delivery; life cycle assessment; total cost of ownership. 


\section{Introduction}

Business-to-consumers (B2C) e-commerce reached a global market value of approximately $€ 2,500$ billion in 2018, growing by $20 \%$ with respect to 2017 . The largest market was China with more than $€ 1,000$ billion ( $+19 \%$ with respect to 2017), followed by USA ( $€ 620$ billion) and Europe ( $€ 600$ billion) — both registering a growth rate of approximately $12 \%$ compared to the previous year (eCommerce B2C Observatory, 2018). The proliferation of e-commerce over the last years has been recognized to have a huge impact on transportation, owing to the increasing need for last mile deliveries (i.e., the transportation of goods purchased online to customers' houses) in urban areas (Schöder et al., 2016). Thus, e-commerce has been claimed to be responsible for the rising number of vans moving in cities (Allen et al., 2010), with a significant impact on environmental sustainability. In today's society, increasing sustainability through the reduction of greenhouse gas (GHG) emissions has become a primary objective to be achieved to improve the quality of life and simultaneously diminish oil dependence (Pieralice and Trepidi, 2016). For the sake of illustration, the Transport White Paper — issued by the Directorate-General for Mobility and Transport, European Commission (28 March 2011) — declared two specific urban goals to be achieved by 2030: (i) halving the use of conventionally fueled cars in cities and (ii) essentially $\mathrm{CO}_{2}$-free logistics in major urban centers. Many studies have investigated the social and environmental footprint of e-commerce last mile deliveries in urban areas, mainly in terms of traffic congestion and atmospheric pollution (e.g., Pieralice and Trepidi, 2016). To mitigate the harmful impact of ecommerce on the environment, researchers have also tried to analyze solutions such as policy initiatives (e.g., road pricing with the aim of better spreading traffic volume over time; licensing and regulation, through which local authorities aim at changing carriers' operations) (Quak, 2011), technologies to innovate vehicles and make them less polluting (Cairns, 2005; Lin and Ho, 2008; Lieb and Lieb, 2010), or alternative fuels such as biodiesel (Cairns, 2005; Fulton and Lee, 2013). Among these solutions, the use of electric vehicles (EVs) for home deliveries seems to be interesting enough to be explored, because it may contribute to both a significant reduction in $\mathrm{CO}_{2}$ emissions and energy savings (Lieb, 2008; Browne et al. 2011). Moreover, EVs have been claimed as a solution to reduce not only gas emissions but also noise pollution (Crainic et al., 2004; Van Mierlo and Maggetto, 2007). In addition to environmental reasons, there are other factors that can foster the adoption of EVs, e.g., the possibility of entering restricted traffic areas (Quak et al., 2016) and lower expenses throughout their lifecycle compared to internal combustion engine vehicles (ICEVs) owing to lower feeding (fuel for ICEVs and electricity for EVs) and maintenance costs (Quak et al., 2016; Lebeau et al., 2015). However, some adoption barriers for EVs have been identified, e.g., higher purchasing costs compared to ICEVs, poorly developed charging infrastructure, low autonomy of batteries, and long charging time required (Quak et al., 2016). Nevertheless, considering all the above-mentioned limitations, EVs today represent a feasible option for short-distance trips in urban areas involving low daily driving range (e.g. Rafique and Town, 2019).

Researches have investigated the economic and environmental competitiveness of EVs compared to their diesel or petrol counterparts. As for the economic analysis, a total cost of ownership (TCO) approach is generally adopted, as it allows the costs related to owning, operating, and holding a vehicle to be included (Al-Alawi et al., 2013). Parameters are generally considered deterministic, but few studies employ probabilistic models (e.g. Wu et al., 2015; Danielis et al., 2018) in order to include variabilities of data. When proposing a TCO on vehicles - regardless of the propulsion systems - different models from different car manufacturers are generally considered. This approach is especially adopted while comparing different models of passenger cars, with the specific aim of investigating different vehicle sizes, user types and drive technologies. For the sake of illustration, the TCO applied to vehicles in Germany revealed that without governmental subsidy only full and mild hybrid electric vehicles are an economically feasible option for some user types (Bubeck et al., 2016). Morrison et al. (2018) estimated instead the TCO for 77 light-duty vehicle segments, defined by driving range and size class. Lebeau et al. (2019) followed the same approach while comparing different electric light commercial vehicles, concluding that only small electric vans (e.g. Goupil e-G4/e-G5, Alke ATX 340e) are competitive with their conventional versions as they need smaller and less expensive batteries. A recent field of research regards instead the public transportation, both from the economic and environmental perspectives (e.g. Zhang et al., 2014). As an example, Topal and Nakir (2018) - relying on a dynamic model based on the TCO from 
well to wheel - revealed that electrical bus concept can be a feasible alternative in the future public transport system in Instabul.

In general, there are many factors that can influence the results, which should be appropriately considered in the assessment. The first among these are economic elements, e.g., the fuel price or the price of vehicles and batteries, which are strongly dependent on the economies of scale in production (Lebeau et al., 2015; Lévay et al., 2017). Second, the government policies, e.g., incentives that can enhance the competitiveness of EVs (e.g. Jenn et al., 2018; Thiel et al. 2010; Zachariadis, 2006). As an example, Bjerkan et al. (2016) investigated the role of incentives in promoting BEV ownership in Norway and they identified seven types of incentives (i.e. exemption purchase tax, exemption vat, exemption road tolling, vehicle license fee reduction, free parking, bus lane access, free ferry tickets). Among them, Norwegian owners of electric vehicles particularly recognize the significance of incentives for reducing purchase costs. Langbroek et al. (2016) recognized instead the free parking or access to bus lanes as an efficient alternative to expensive subsidies. Third, vehicle-usage-related factors, e.g., utilization rate and ownership period. In particular, EVs do not seem to be competitive under low utilization rates (e.g., Feng and Figliozzi, 2012, Lebeau et al., 2015). EVs benefit from long ownership periods, owing to lower operational cost (Al-Alawi and Bradley, 2013; Wu et al., 2015). In general, TCO is affected by the peculiarities of the selected area to which it is applied (e.g., Breetz and Salon, 2018; Danielis et al., 2018). Breetz and Salon (2018) analyze the five-year TCO for conventional, hybrid, and electric vehicles in 14 US cities from 2011 to 2015: results show variations due to differences in state and local incentives policies, energy prices, insurance cost, maintenance costs, depreciation rates, and kilometers travelled.

It is therefore necessary to notice that the comparison between EVs and ICEVs is not easy, as all these elements should be considered appropriately. Moreover, some of the factors mentioned above can change over time (e.g., fuel or energy price), making the ex-ante evaluation more difficult.

Considering the environmental perspective, the sustainability of an EV, compared to that of a traditional ICEV, is generally evaluated through life cycle assessment (LCA). As for economic evaluation, the results depend on different factors, e.g., the characteristics of the country, the type of vehicles, the charging infrastructure, the generation mix (e.g. Mills and MacGill, 2017). Moreover, environmental impact can be measured through different metrics. According to the metric used, the choice of the "best" solution between EVs and ICEVs can change. For example, when the impact on human toxicity is considered, EVs using lithium ion batteries have the highest negative impact (de Souza et al., 2018); when the impact on abiotic depletion or global warming is considered, ICEVs cause the highest negative impact owing to fuel consumption (de Souza et al., 2018; Yu et al., 2018; Wu et al., 2018).

Briefly, literature provides with many studies comparing TCO of vehicles with different propulsion systems (e.g. electric, hybrid, internal combustion and others). Moreover, the passenger segment is particularly tackled, since the most common aim is to compare TCO of different car segments - targeting indeed customers and policy makers towards the awareness of potential need of incentives. Literature investigates also the wide range of parameters to be considered while making an economic assessment, as well as the related impact on the overall result. Anyway, results of the studies strictly depend on the context (e.g. region, country) considered. These being the premises, the present work aims to provide a comparison between EVs and ICEVs used to perform last mile deliveries in B2C e-commerce, considering both economic and environmental perspectives. On the one hand, last mile delivery is indeed very peculiar if compared to the passenger car sector. As an example, some of the barriers pertaining the EVs (e.g. low autonomy of batteries, and long charging time required) may not be the same for express couriers: a delivery tour usually does not overcome a certain number of kilometers, and thus charging is required only after the delivery tour of the day. On the other hand, in Italy there are some differences, beyond the typical operating costs (such as maintenance, repair, energy), which would be interesting to be investigated. This is the case of the road toll to be paid to enter the city center of one of the largest cities in Italy, Milan - which is also the city with one of the highest number of e-commerce orders in the country. As for the evaluation of the environmental impact, the LCA method was adopted, and GHG emissions were chosen as the metric to be measured during the vehicle life cycle (i.e., the production of the fuel, its 
combustion owing to the vehicle usage, as well as the production and disposal of the vehicle). The economic evaluation, however, is based on the TCO analysis, which considers both capex (capital expenditure) and opex (operating expenditure), and allows the comparison between the two types of vehicles throughout the ownership period.

The remainder of this paper is organized as follows. Section 2 describes the methodology adopted within the study and provides information about the employed inputs, both in terms of values and sources. Section 3 reports the main findings. Section 4 presents the sensitivity analyses on the main input. The final section presents the conclusions and the research limitations identified.

\section{Material and methods}

The TCO and LCA analyses are, respectively, used for economic and environmental assessments. The methods are applied to a specific Italian city. Indeed, the reference city, and not only the country itself, affects the cost computation. For example, road toll varies, if provided, according to the city where the van delivers. Milan was selected for the evaluation, as it is a city with one of the highest number of e-commerce orders in Italy. A sensitivity analysis is performed thereafter to test the robustness of the results. In particular, the main objective is to identify the relevant drivers affecting the economic and environmental comparison between EVs and ICEVs.

\subsection{Economic assessment}

Figure 1. Framework for the economic assessment

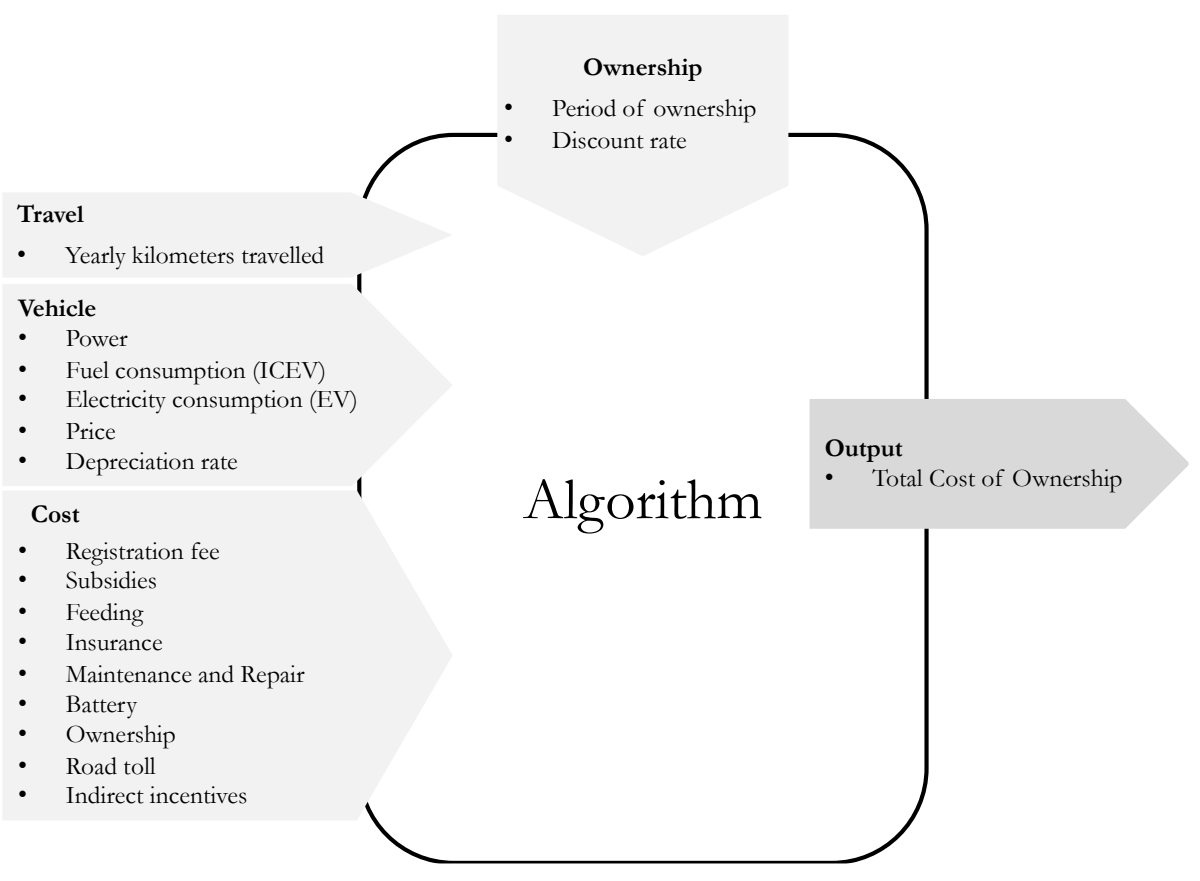

The economic comparison between diesel and electric vans relies on the framework illustrated in Figure 1. Three types of inputs are needed to feed the algorithm aimed at calculating the TCO: (i) travel data (i.e., yearly kilometers travelled), (ii) vehicle data (e.g., power, fuel or electricity consumption, depreciation rate), and (ii) cost data (e.g., electricity or fuel price, road toll). Based on these inputs, the algorithm can be used to estimate the annual operating costs. For example, the annual fuel cost for ICEVs originates from fuel consumption (vehicle input), fuel price (cost input), and number 
of kilometers travelled annually (travel input). Moreover, the period of ownership and the discount rate are needed to evaluate the costs over the lifetime of the vehicle.

\subsubsection{Travel data}

A courier service is assumed to enter the city center every working day to perform the deliveries. In particular, 260 days per year are assumed, and an average trip of $80 \mathrm{~km}$ per day is set by interviewing the three top Italian express courier service providers.

\subsubsection{Vebicle data}

Specific vehicle models were selected, as most costs depend on the features of the van. As for the EV, the 2016 European electric van, which reached a market share of $70 \%$ in its segment (i.e., e-LCVs, electric light commercial vehicles), was chosen. As far as the ICEV counterpart is concerned, the diesel version of the same type of vehicle was selected. The vehicles were assumed to be purchased on 1 January 2018. Table 1 summarizes the characteristics of the two vans that are used in the economic assessment.

Table 1. Characteristics of the vehicles

\begin{tabular}{|l|l|l|}
\hline & ICEV & EV \\
\hline Max power (kW) & 81 & 80 \\
\hline Urban fuel consumption (1/100km) & 5.5 & - \\
\hline Electricity consumption (kWh/100km) & - & 16.5 \\
\hline Purchase price (€) & 17,131 & 32,690 \\
\hline Depreciation rate [\%/year] & 18.57 & 24.43 \\
\hline
\end{tabular}

To compute certain operational costs (e.g. the registration fee), vehicle power, urban fuel, and electricity consumption for urban driving are considered. Purchasing price, which is retrieved from the car manufacturing company website, is the amount of money spent for buying a vehicle. Relying on real life prices is commonly adopted in literature (e.g. Danielis et al., 2018; Hagman et al., 2016). Depreciation rate, instead, is needed to calculate the residual value of the vehicle, i.e., the value of the vehicle at the end of the ownership period. Indeed, each year the value of the van is reduced by the depreciation rate, which is slightly higher in the case of EVs (Lebeau et al., 2015).

\subsubsection{Cost data}

Table 2 reports all the cost inputs used for the TCO computation. They are:

- Registration fee - This amount should be paid when a new vehicle is bought. The amount depends on the weight of the vehicle and its $\mathrm{CO}_{2}$ and $\mathrm{NO}_{x}$ emissions. The regulation criteria for EVs and ICEVs may be different. In Milan, a vehicle with more than $53 \mathrm{~kW}$ - either a diesel or an electric one — is subjected to the payment of a base amount of $150.81 €$ and an additional amount of $4.5655 €$ for each extra $\mathrm{kW}$ exceeding the $53 \mathrm{rd} \mathrm{kW}$.

- Subsidies - Benefits that the government may provide to the companies - usually in the form of a cash payment or a tax deduction - when buying an electric van (Lévay et al., 2017). Italy did not give any type of support in 2018.

- Feeding - This represents the fuel or electricity cost. Fuel and electricity prices in Milan are retrieved from Global Petrol Prices. 
- Insurance - The annual fee paid for ensuring damages caused to other vehicles and involving people in a collision. Insurance and, in particular, civil liability are compulsory in Italy. EVs benefit from a reduction in the annual cost of approximately 30\% when compared to ICEVs. The insurance cost is calculated as the average of the fee proposed by three insurance companies. In particular, the three top players in the Italian market were selected. The insurance cost is assumed to remain constant during the ownership period.

- Maintenance and repair - Expected annual amount of money dependent on the usage rate of the vehicle. Maintenance and repair costs for the EVs are expected to be lower than those for ICEVs. According to Fischer et al. (2009), the difference in cost of both solutions is a consequence of the small number of moving parts that electric vehicles have as compared to ICEVs. Additionally, EVs face less temperature stress and do not need oil changes and filter replacements (Fischer et al., 2009). The maintenance and repair cost is based on ACI (Automobile Club d'Italia) estimations.

- Ownership - Annual tax associated with the ownership of the vehicle, if provided by the government. Regulation criteria may differ between EVs and ICEVs. The annual circulation tax is calculated by region in Italy - Lombardia in the case of Milan - according to the engine power of the vehicle (kW), i.e., $2.58 € / \mathrm{kW}$. Ownership cost need not be paid for EVs.

- Road toll - Fee to enter a city, if provided. According to what is reported by the Milan municipality, electric vehicles are exempt from road toll payment. However, diesel vans pay $3 €$ for each day they enter the city center.

- Indirect incentives - The Italian fiscal system does not differentiate between electric and diesel vehicles for the deductibility of corporate taxes.

Table 2. Cost elements for EVs and ICEVs

\begin{tabular}{|l|l|l|}
\hline & ICEV & EV \\
\hline Registration fee (base amount) $[€]$ & 150.81 & 150.81 \\
\hline Registration fee (extra amount) $[€ / \mathrm{kW}]$ & 4.5655 & 4.5655 \\
\hline Subsidies & - & - \\
\hline Feeding [€/u.o.m.] & $1.55[€ / \mathrm{l}]$ & $0.2[€ / \mathrm{kWh}]$ \\
\hline Insurance [€/year] & 711 & 452 \\
\hline Maintenance and repair [€/km] & 0.06249 & 0.0435918 \\
\hline Ownership [€/kWh] & 2.58 & - \\
\hline Road toll [€/day] & 3 & - \\
\hline
\end{tabular}

\subsubsection{Ownership}

The period of ownership is a key parameter to be defined to compute TCO. Moreover, as the operational costs are distributed across the entire considered lifespan of the vehicle, a discount rate is needed to merge the costs pertaining to different years. The discount rate can be defined as "the rate of interest reflecting the investors' time value of money" (Mearig et al., 1999).

The period of ownership, i.e., 8 years, has been retrieved by the European Environment Agency. As a consequence, the Italian long-term interest rate of state (i.e., $0.82 \%$ ) is considered as the discount rate (Decreto Direttoriale 18/12 2017, Ministero dello Sviluppo Economico). 


\subsubsection{Total Cost of Ownership}

The TCO computed for a certain period $T$ is calculated using formula (1).

$\mathrm{TCO}_{T}=\mathrm{PP}_{0}-\mathrm{RV}_{T}+\mathrm{RFC}_{0}-S_{0}+\sum_{\mathrm{t}=0}^{\mathrm{T}=} \frac{\mathrm{FC}_{\mathrm{t}}+\mathrm{IC}_{\mathrm{t}}+\mathrm{MRC}_{\mathrm{t}}+\mathrm{BC}_{\mathrm{t}}+\mathrm{OC}_{\mathrm{t}}+\mathrm{RT}_{\mathrm{t}}-\mathrm{II}_{\mathrm{t}}}{(1+\mathrm{i})^{\mathrm{t}}}$

where $\mathrm{PP}$ is the purchasing price, $\mathrm{RV}$ is the residual value, $\mathrm{RFC}_{0}$ is the registration fee cost, $S_{0}$ denotes the subsidies, FC is the feeding cost (electricity cost for EVs, fuel cost for ICEVs), IC is the insurance cost, MRC is the maintenance and repair cost, $\mathrm{BC}$ is the battery cost (in case of electric vehicles), OC is the ownership cost, RT is the road toll, II are the indirect incentives, $T$ is the ownership period, and $i$ is the discount rate

In particular,

- $\operatorname{RV}_{T}[€]=$ Purchasing price $\times(1-\text { Depreciation rate })^{T}$

- $\quad \mathrm{FC}_{t}\left[\frac{€}{y}\right]=$ Price $\left[\frac{\epsilon}{\text { u.o.m. }}\right] \times$ Consumption $\left[\frac{\text { u.o.m. }}{\mathrm{km}}\right] \times$ Yearly km where u.o.m. is the unit of measure for fuel (i.e., liter) or electricity (i.e., kWh)

- $\operatorname{MRC}_{t}\left[\frac{€}{y}\right]=\operatorname{mrc}\left[\frac{€}{\mathrm{~km}}\right] \times$ Yearly $\mathrm{km}$

where mrc is the expected maintenance and repair cost per kilometer

- $\mathrm{OC}_{t}=$ Power $[\mathrm{kW}] \times$ oc $\left[\frac{€}{\mathrm{~kW}}\right]$

where oc is the unitary cost per $\mathrm{kW}$

- $\quad \mathrm{RT}_{t}=\operatorname{road}$ toll $\left[\frac{€}{\text { day }}\right] \times$ Yearly working days $\left[\frac{\text { days }}{\text { year }}\right](7)$

While the purchasing price, registration fee, and subsidies are evaluated only in the first year of the ownership period (i.e., $t=0$ ), the residual value pertains to the last year (i.e., $T$ ). All the other cost elements are accounted for each year. Moreover, as 8 years is the period for which the battery of EVs is covered by the car manufacturer warranty, the battery replacement cost can be considered null in the TCO assessment.

\subsection{Environmental assessment}

Environmental assessment for a diesel or electric van relies on the framework illustrated in Figure 2. 
Figure 2. Framework for the environmental assessment

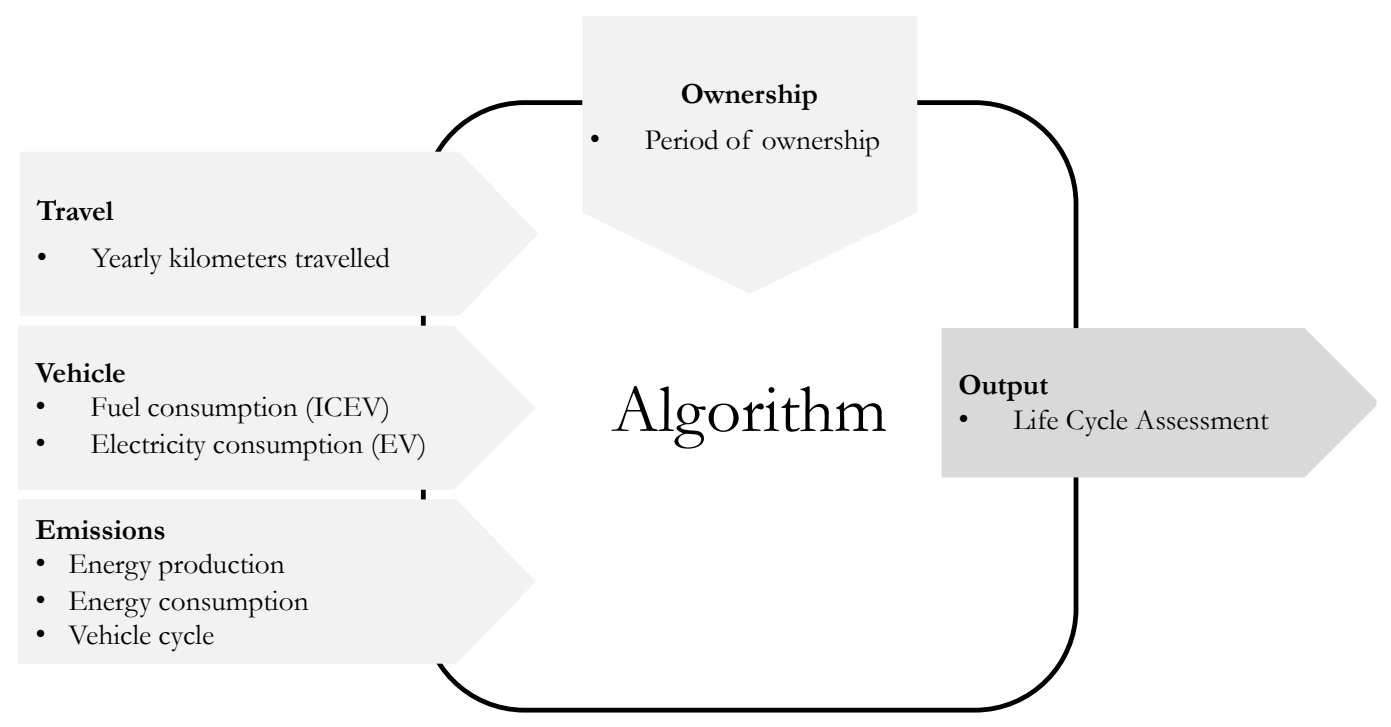

Similar to economic assessment, three types of inputs are needed to come up with the output, i.e., LCA for both the EVs and the ICEVs: (i) vehicle data, (ii) emissions data, and (iii) travel data. Besides, emissions are evaluated over the entire period of ownership, which represents a significant parameter for the assessment. Vehicle data includes information such as fuel or electricity consumption. Travel input, as in economic analysis, is represented by the number of kilometers travelled in a year. The emissions are instead evaluated based on three sources: (i) energy production, (ii) energy consumption, and (iii) vehicle cycle. In particular:

- Energy production refers to the GHG emissions from the production of fuel or electricity. Referring to fuel, it covers its extraction, refinement, transportation, and distribution. As for electricity, energy production emissions include its generation (considering the country-based electricity mix), transmission, and distribution. According to Report 280/2018 by ISPRA (Istituto Superiore per la Protezione e la Ricerca Ambientale), an Italian public entity of the Environment Ministry, the average GHG emission produced by electricity in Italy was $325.2 \mathrm{gCO}_{2} \mathrm{e} / \mathrm{kWh}$ in 2017 . On the contrary, according to the report WELL-TOTANK, version 4.0, published on 4 July 2013 by the European Commission (European Commission, 2011), the GHG emissions produced by 1 liter of diesel is $547.2 \mathrm{gCO}_{2} \mathrm{e} / 1$.

- Energy consumption refers to the GHG emissions related to vehicle use. While ICEV emissions are attributed to fuel combustion, EVs do not produce GHG emissions when they are moving. For ICEVs, in travelling for a kilometer, the vehicle releases $130 \mathrm{gCo} 2 \mathrm{e}$. This information is provided by the car manufacturer.

- Vebicle cycle considers all the GHG emissions related to production including raw material and components acquisition and processing, maintenance, and disposal of the vehicle. GHG emissions related to the diesel vehicle cycle were collected according to a study published by the European Federation for Transport and Environment in September 2017 named "Diesel: The True Story." The diesel van considered in the present study, according to the guidelines of this report, is classified as a midsize one. Thus, it emits 6.24 tonnes of $\mathrm{CO}_{2}$ e, considering its production (as well as raw material and component processing) and disposal. GHG emissions related to EVs are 8.5 tonnes of $\mathrm{CO}_{2} \mathrm{e}$ (Wu et al., 2018).

Table 3 summarizes all the GHG emissions used as inputs for environmental assessment. 
Table 3. GHG Emissions

\begin{tabular}{|l|l|l|}
\hline & EV & ICEV \\
\hline Energy production & $325.2\left[\mathrm{gCO}_{2} \mathrm{e} / \mathrm{kWh}\right]$ & $547.2\left[\mathrm{gCO}_{2} \mathrm{e} /\right.$ liter $]$ \\
\hline Energy consumption $[\mathrm{gCO} 2 \mathrm{e} / \mathrm{km}]$ & - & 130 \\
\hline Vehicle cycle $\left[\right.$ ton $\left.\mathrm{CO}_{2} \mathrm{e}\right]$ & 8.5 & 6.24 \\
\hline
\end{tabular}

\section{Results and discussion}

\subsection{Economic assessment}

Based on the inputs and formulas reported in Section 2, the TCO is calculated and the overall results are shown in Figure 3. Table 4 reports the cost per kilometer, which is computed by dividing the TCO by the total number of kilometers covered in 8 years, and the distribution of each cost element shaping the TCO - as suggested in Wu et al. (2015).

Figure 3. Total Cost of Ownership for EV and ICEV in Italy

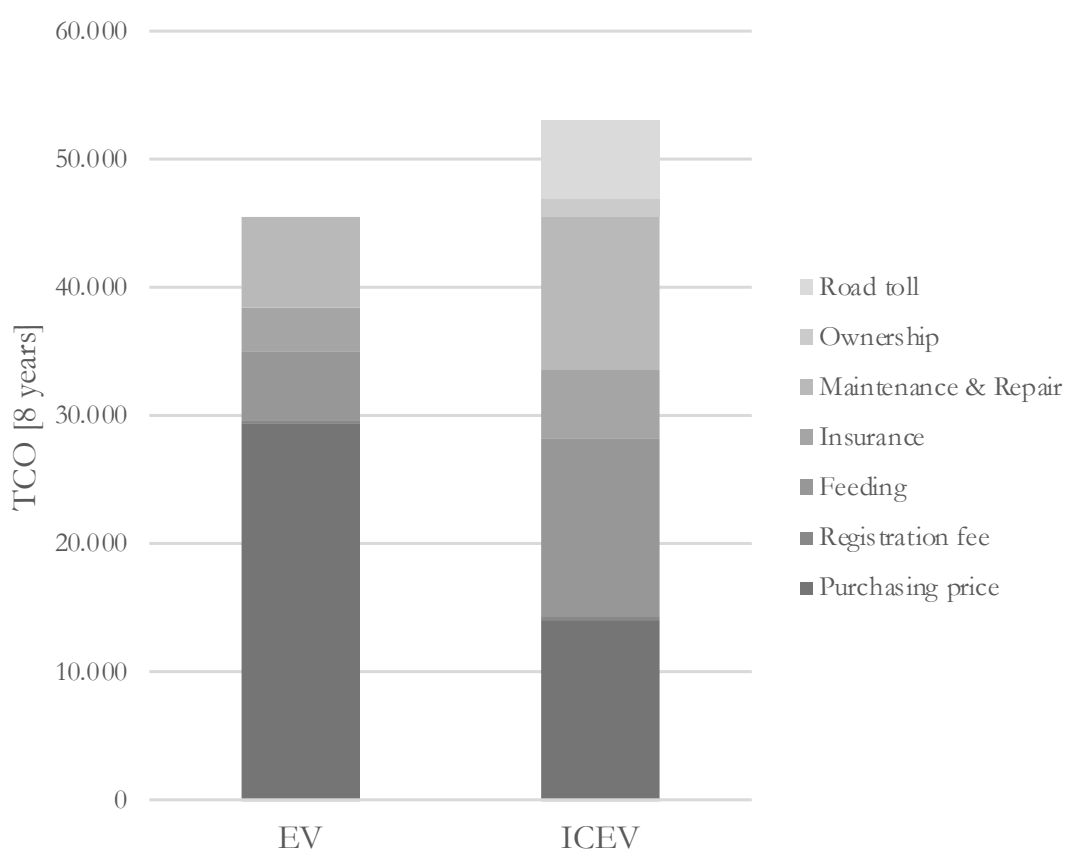

Table 4. Cost per kilometre and cost element distribution for EVs and ICEVs

\begin{tabular}{|c|c|c|c|c|c|c|}
\hline & \multicolumn{2}{|l|}{ EV } & \multicolumn{2}{|l|}{ ICEV } & \multicolumn{2}{|c|}{$\Delta(\mathrm{ICEV}-\mathrm{EV})$} \\
\hline & $€$ cent $/ \mathrm{km}$ & $\%$ & $€$ cent $/ \mathrm{km}$ & $\%$ & $€$ cent $/ \mathrm{km}$ & $\%$ \\
\hline Purchasing price & 0.1767 & 64.74 & 0.0842 & 26.40 & -0.0926 & -52 \\
\hline Registration fee & 0.0016 & 0.60 & 0.0017 & 0.53 & +0.0001 & +2 \\
\hline Feeding & 0.0311 & 11.39 & 0.0829 & 25.99 & +0.0518 & +166 \\
\hline Insurance & 0.0211 & 7.74 & 0.0332 & 10.43 & +0.0121 & +57 \\
\hline Maintenance and Repair & 0.0424 & 15.52 & 0.0706 & 22.15 & +0.0282 & +67 \\
\hline Ownership & - & - & 0.0098 & 3.06 & +0.0098 & - \\
\hline Road toll & - & - & 0.0364 & 11.43 & +0.0364 & - \\
\hline Total cost & 0.2730 & & 0.3188 & & +0.0458 & +17 \\
\hline
\end{tabular}


Considering the annual mileage assumed by the study (approximately 20,800 km/year), EVs are a competitive alternative to ICEVs in Milan. While the TCO for an EV is approximately 45,500 €, the TCO for an ICEV is nearly $17 \%$ higher, thus exceeding 50,000 €. Even if the purchasing price is almost doubled in the case of EVs (approximately $32,000 €$ for an EV and 17,000 € for an ICEV), the operating expenditure of the ICEV increases its TCO. In particular, the total operating cost for EVs and ICEVs, respectively, accounts for 35\% and 73\% of their TCO.

The main cost advantages of EVs are the maintenance and repair cost and the feeding cost. In particular, the maintenance and repair cost for an electric vehicle is approximately $40 \%$ lower than that for an ICEV (e.g. Lebeau et al., 2019; Danielis et al., 2018), which can be attributed to the nature of EVs, as electric engines employ less moving parts than internal combustion engines. Moreover, the total energy cost of the EVs is approximately $60 \%$ lower than the fuel cost for ICEVs. In the end, there is an additional benefit for EVs stemming from lower insurance cost, i.e., by approximately $35 \%$.

Road toll strongly affects the overall result. Indeed, it represents approximately $11 \%$ of the TCO for ICEVs. If road toll were not implemented, or if it were implemented for electric vans as well, the TCO for EVs and ICEVs would be nearly equal. The ownership cost is the other cost element that is considered only in the case of diesel, as it is not required to be paid for EVs in Italy. By the way, accounting for only $3 \%$ of the overall TCO, the ownership cost is not as impactful as the road toll. The results of the comparison between EVs and ICEVs depend on the ownership period. In this regard, Figure 4 represents the cumulative TCO computed for each year of ownership. It emerges that the breakeven point, after which EVs become economically more feasible than ICEVs, is nearly 4.5 years of ownership. Indeed, the high purchasing price of EVs negatively affects the competitiveness of the electric solution in the first years.

Figure 4. TCO (t) for EVs and ICEVs

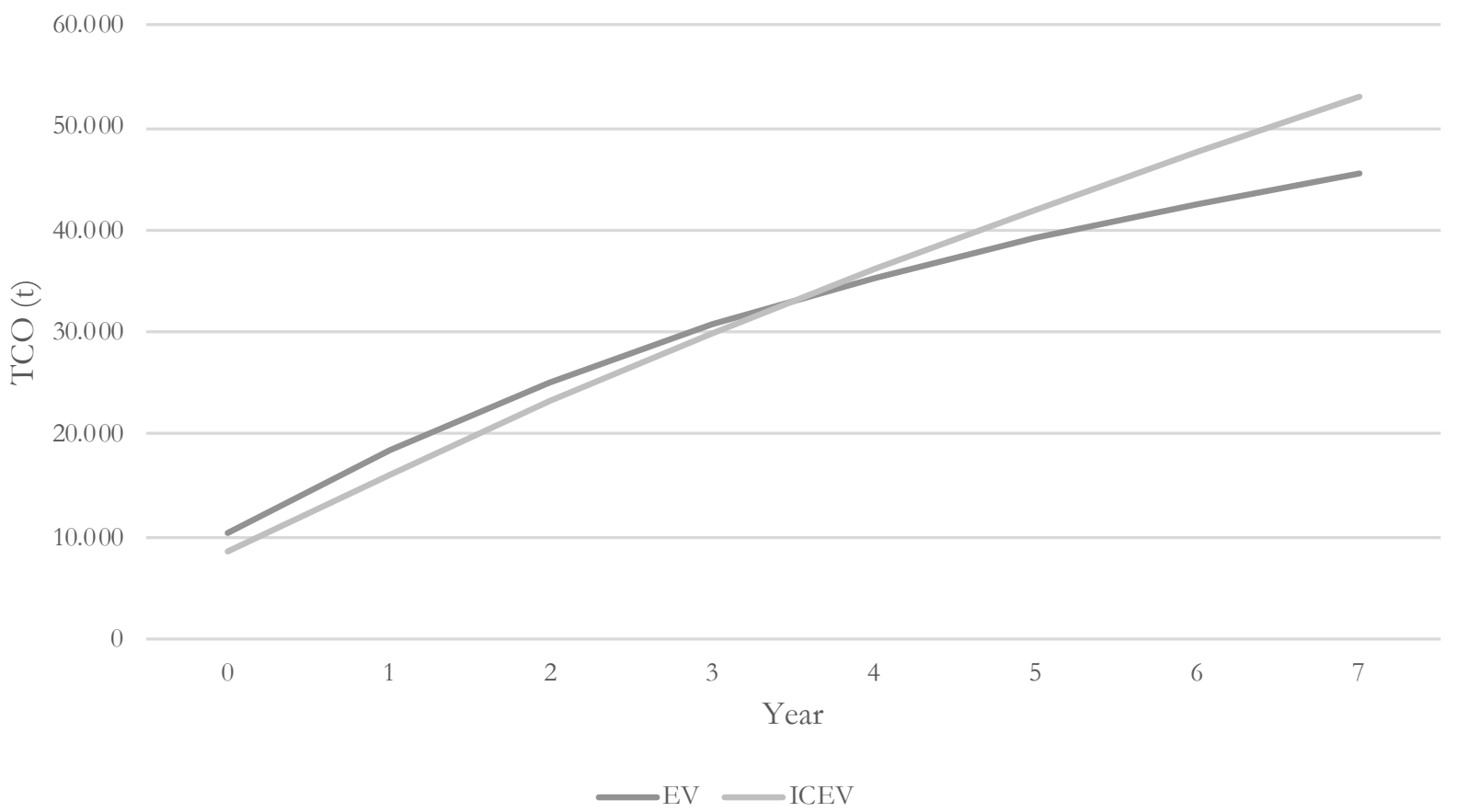

\subsection{Environmental assessment}

Figure 5 illustrates the results of the LCA comparison between EVs and ICEVs from an environmental perspective. Considering an 8-year lifecycle for the vehicles, EVs release nearly half of the GHG emissions as compared to ICEVs. 
Even if the energy production and vehicle-cycle emissions are higher for EVs-respectively, approximately $+40 \%$ and $+27 \%$ compared to ICEVs_- diesel consumption leads to a major part of the ICEV emissions (i.e., approximately $66 \%$ ). Moreover, while emissions related to diesel consumption have a "local" incidence, emissions related to energy production and vehicle cycle are not confined to the region within which the van travels. Thus, this result is extremely relevant for municipalities that aim at reducing GHG emissions within their districts.

Figure 5. GHG emissions for EVs and ICEVs

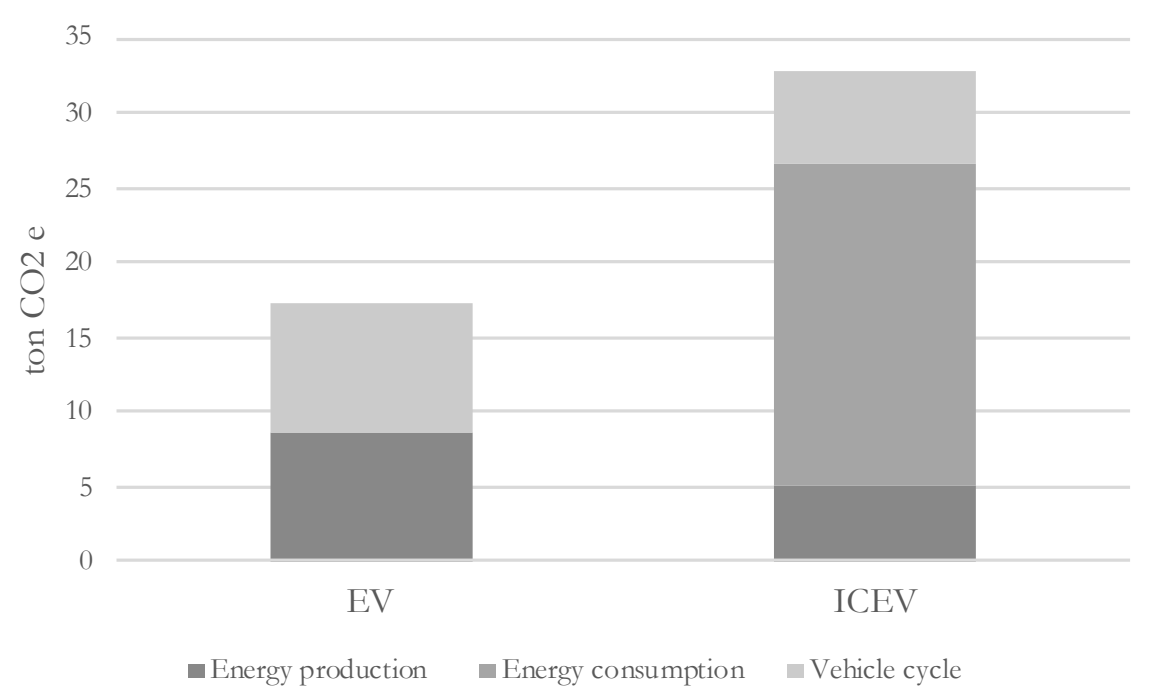

Italy registered about 270 million deliveries in 2018 (eCommerce B2C Observatory, 2018). Interviews with the three top Italian express courier service providers in Italy revealed that about 15\% of the overall B2C deliveries are concentrated in the city of Milan. Assuming furthermore 260 working days per year and about 80 deliveries in 8 -hours delivery tour (see section 2.1.1), about 1,950 van daily access the city of Milan. Considering the local emissions related to the diesel consumption of an ICEV (i.e. $130 \mathrm{gCO}_{2} \mathrm{e} / \mathrm{km}$ - see section 2.2), the substitution of an ICEV with an EV allows saving 2,7 tonnes of $\mathrm{CO}_{2}$ e per year. Thus, the substitution of the entire fleet stock daily accessing the city will allow avoiding about 5,265 tonnes of $\mathrm{CO}_{2} \mathrm{e}$ per year.

\subsection{Sensitivity analyses}

Four sensitivity analyses are carried out to test the reliability of the results by varying the main inputs (i.e., the number of kilometers travelled, road toll, purchasing price, fuel and electricity prices). While the number of kilometers travelled affects both the economic and environmental results, the road toll impacts only the TCO.

\subsubsection{Number of kilometers travelled}

A sensitivity analysis is proposed on the number of daily kilometers travelled, and thus on the total mileage during the entire ownership period. Indeed, as it is clear, some components of the operating expenditures are strongly affected by the number of kilometers travelled. In particular, the feeding cost and maintenance and repair cost, considered together, represent $80 \%$ of the total operative cost for EVs and $65 \%$ for ICEVs.

Figure 6 reports the cost per kilometer in six different contexts, each represented by a different daily mileage (i.e., 20, $40,60,80,100$, and $120 \mathrm{~km} /$ day). The cost for EVs and ICEVs is nearly equal when 40 kilometers are covered each working day (i.e., 83,200 km in 8 years). Beyond this threshold, always considering an 8-year ownership-the employment of an electric van is no more economically feasible. However, it should be stated that when considering 
last mile deliveries for B2C e-commerce, mileages under $40 \mathrm{~km} /$ day are very rare and therefore EVs prove to be more beneficial than ICEVs.

On the contrary, the more number of kilometers the van travels, the higher are the savings related to EVs. If we consider 60 daily kilometers, the cost of operating EVs turns out to be $10 \%$ lower than that of ICEVs. Taking as a reference the context with the highest mileage (i.e., $120 \mathrm{~km} /$ day), EVs allows saving 30\% of the total ownership cost. It is necessary to notice that for the purpose of the present study, battery autonomy does not represent a barrier for the adoption of EVs. In fact, considering the battery capacity (i.e., $40 \mathrm{kWh}$ ) and the energy consumption (i.e., 16 $\mathrm{kWh} / 100 \mathrm{~km}$ ), the autonomy turns out to be $250 \mathrm{~km}$. This value is significantly higher than the expected number of kilometers travelled per day in the last context (i.e., $120 \mathrm{~km} /$ day) and three times higher than the average value considered in the base case (i.e., $80 \mathrm{~km} /$ day).

Figure 6. Cost per kilometer considering different mileage and 8 years ownership

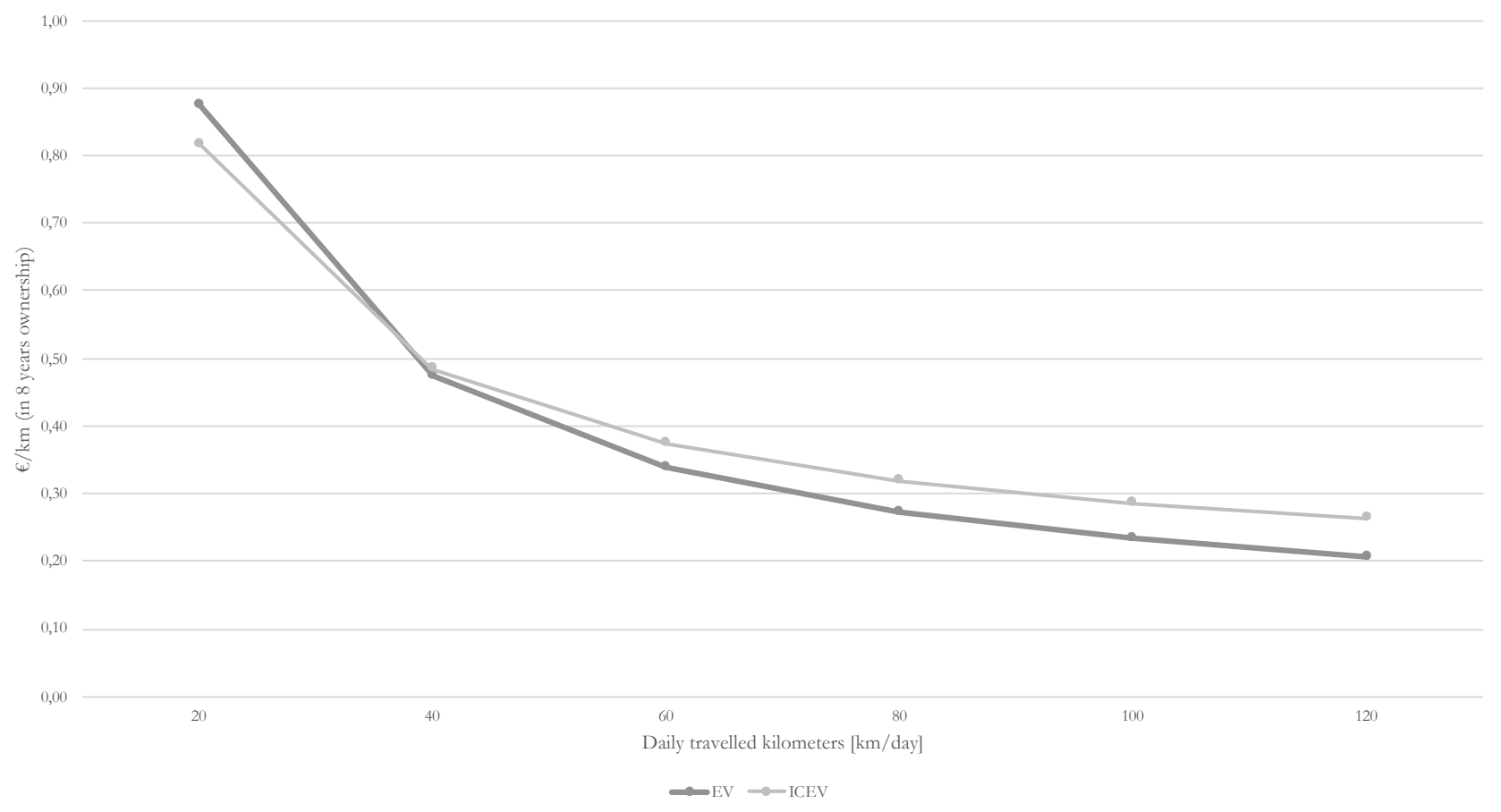

The number of kilometers impacts not only the costs but also the GHG emissions. Figure 7 reports how the results for EVs and ICEVs change for different mileages. It is clear that EVs are always better than ICEVs from an environmental perspective: the reduction of GHG emissions derived from the replacement of ICEVs with EVs varies between $-17 \%$ (considering $20 \mathrm{~km} /$ day) and -54\% (considering $120 \mathrm{~km} /$ day). 
Figure 7. GHG Emissions considering different mileages and 8 years ownership

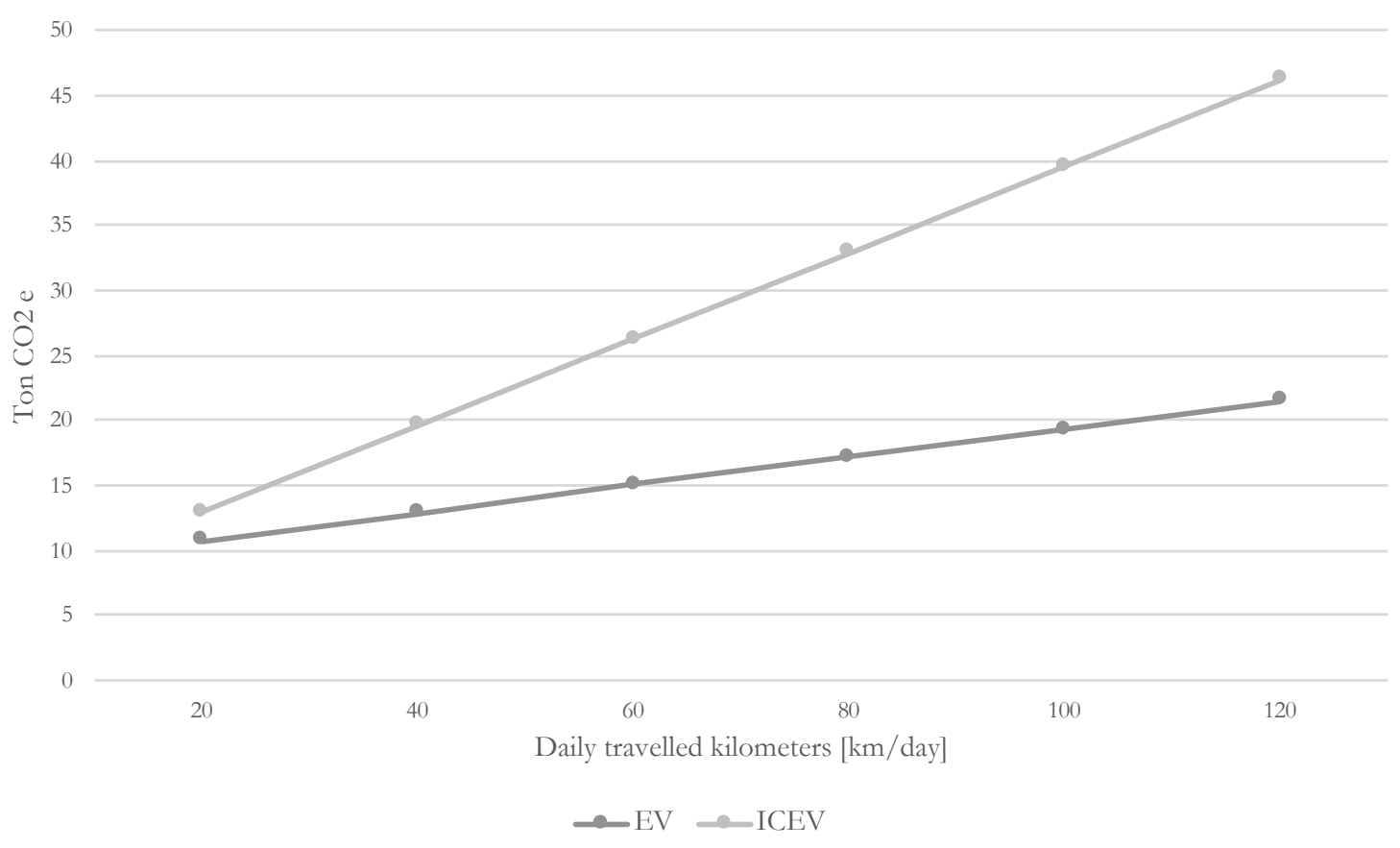

\subsubsection{Road toll}

Another significant element affecting the result is the road toll, which accounts for $11 \%$ of the TCO in the case of ICEVs. In a context where road toll is not implemented by the municipality, the breakeven point of the investment to replace ICEVs with EVs moves to the 7th year of ownership, compared to year 4.5 of the base case considered.

Figure 8. TCO (t) for EV and ICEV with no road toll

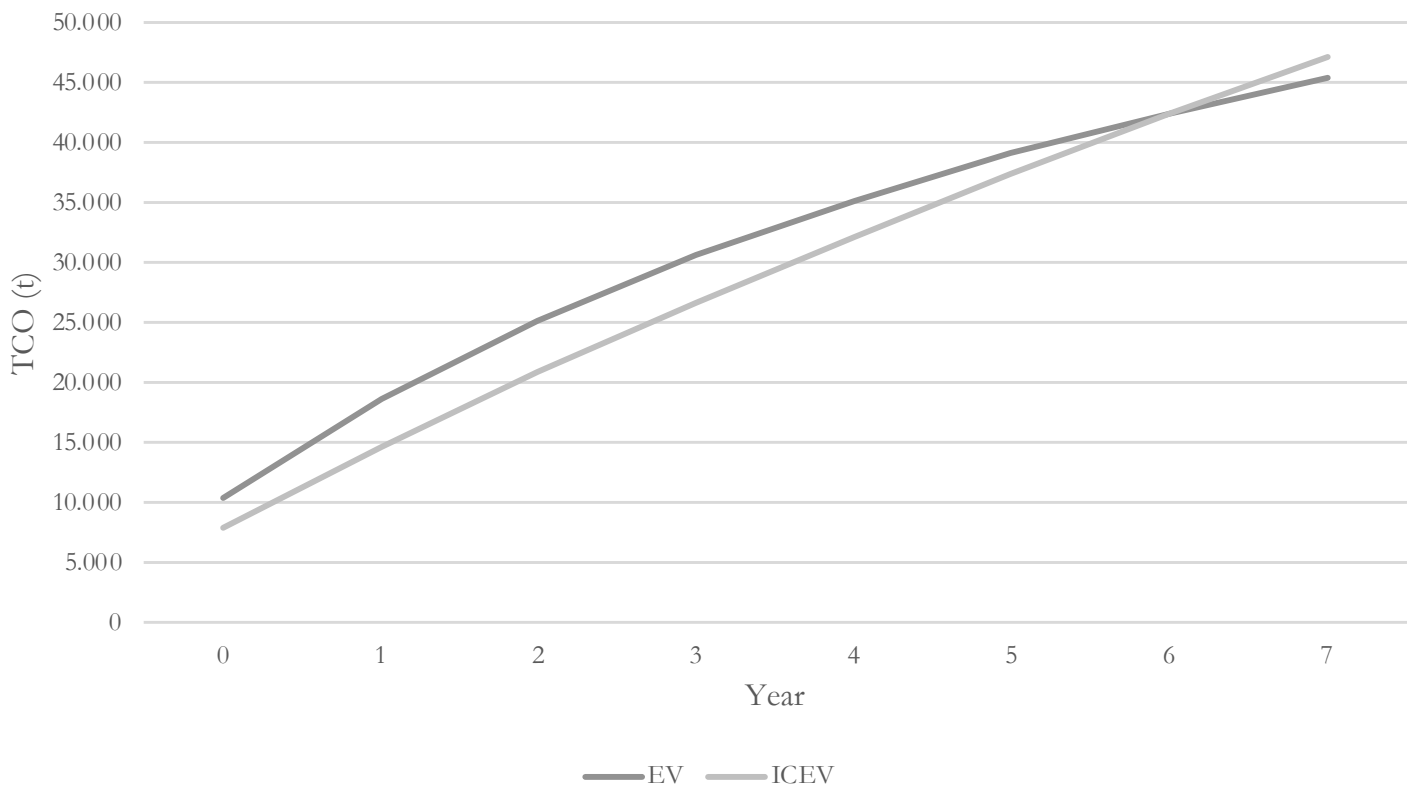




\subsubsection{Purchasing price}

The present study focuses on a specific type of vehicle, the 2016 European electric van, and it considered the diesel counterpart. Anyway, the market offers a wide range of vehicles (Lebeau et al., 2019). Other studies comparing different types of vehicles typically investigate TCO of different passenger cars (e.g. Cox et al., 2020; Breetz and Salon, 2018; Hagman et al., 2016) with the aim of showing the ownership cost of vehicles with very different characteristics (e.g. size, market segment, and therefore price). As an example, Letmathe and Suares (2017) propose a TCO for passenger vehicle models with different vehicle segments (i.e. mini, small, medium, large, executive, luxury, SUV). When considering deliveries in B2C e-commerce, vehicles have indeed very similar characteristics, especially in terms of size, capacity and fuel or electricity consumption. Anyway, based on the brand, the price varies. In this regard, a sensitivity analysis on the purchasing price is proposed. Relying on the price of three electric vans (i.e. Citroen eBerlingo Multispace, Peugeot Partner Full Electric and Renault Kangoo Z.E.) and their diesel counterparts, the lowest and the highest price are considered the basis for the sensitivity analysis. In particular, a scenario analysis is proposed. The highest purchasing price for an electric vehicle is $€ 33,000$ (i.e. Peugeot Partner Full Electric), while it is $€ 17,131$ for the diesel one (i.e. NV250). The lowest prices are instead $€ 25,000$ (i.e. Renault Kangoo Z.E.) and $€ 14,580$ (i.e. Citroen Berlingo Multispace). As represented in Table 5, four scenarios are potentially identified. First, both the electric and the diesel vans displays the highest prices: this is anyway very close to the results already shown in section 3.1, where the e-NV200 is valued $€ 32,690$ and the diesel counterpart is $€ 17,131$. Second, the purchasing price of the electric van is still "high", but the price of the diesel one decreases, being it "low". Third, both the prices are considered "low". In the end, the electric van has the lowest price while the diesel van has the highest one. Based on the results in 3.1, the electric van resulted to be competitive: a decrease in its price coupled with an increase in the diesel van price will not bring to new results.

Even by varying the purchasing prices of the vans, EVs result competitive if compared to ICEVs - when the road toll entering the city center of the city is required (see Table 6). Considering instead the case of another potential municipality without the duty of the road toll, the TCO of an ICEV is slightly lower in scenario II (i.e. electric van has the highest price and the diesel van has the lowest).

Table 5. Scenario analysis based on the purchasing prices of EVs and ICEVs

\begin{tabular}{|l|c|c|c|c|}
\hline (Purchasing Price) & Scenario I & Scenario II & Scenario III & Scenario IV \\
\hline EV & P.P. High & P.P. High & P.P. Low & P.P. Low \\
\hline ICEV & P.P. High & P.P. Low & P.P. Low & P.P. High \\
\hline
\end{tabular}

Table 6. TCO in purchasing prices scenarios I, II and III

\begin{tabular}{|l|c|c|c|c|c|c|}
\hline \multirow{2}{*}{ TCO $[\epsilon]$} & \multicolumn{2}{|c|}{ Scenario I } & \multicolumn{2}{c|}{ Scenario II } & \multicolumn{2}{c|}{ Scenario III } \\
\cline { 2 - 6 } & Road Toll & No Road Toll & Road Toll & No Road Toll & Road Toll & No Road Toll \\
\hline EV & \multicolumn{2}{|c|}{45,423} & \multicolumn{2}{|c|}{45,423} & \multicolumn{2}{c|}{38,505} \\
\hline ICEV & 53,043 & 46,978 & 50,957 & 44,892 & 50,957 & 44,892 \\
\hline
\end{tabular}

\subsubsection{Fuel and electricity price}

The fuel cost is usually the largest operating cost (e.g. Palmer et al., 2018). In the present analysis, fuel cost represents indeed the $26 \%$ of the TCO of an ICEV, the second most impactful cost after the purchasing price. As in Breetz and Salon (2018), different diesel and electricity price scenarios are assumed. Similarly to the purchasing price (section 3.3.3), a scenario analysis is proposed. The Italian Ministry of Economic Development provides with open data on the weekly prices of fuels from 2010 (Ministero Sviluppo Economico, 2020). The lowest $(1.135 € / 1)$ and the highest (i.e. 
$1.778 € / \mathrm{l}$ ) prices of diesel are considered in the analysis. ARERA (i.e. Autorità di Regolazione per Energia Reti e Ambiente) (2020), the Italian Regulatory Authority for Energy, Networks and Environment, provides instead with quarterly data on electricity prices along years. The lowest (i.e. $0.1557 € / \mathrm{kWh})$ and the highest $(0.22 € / \mathrm{kWh})$ prices from 2010 are considered as well. Results in section 3.1 assumed $1.55 € / 1$ and $0.2 € / \mathrm{kWh}$ respectively for the diesel and electricity prices. As in 3.3.3., four scenarios based on the fuel and the electricity prices (i.e. "low" or "high") are represented.

In each scenario identified, EV is competitive if compared to ICEV - when the road toll entering the city center of the city is required (see Table 7). Without the duty of the road toll, TCOs of EV and ICEV are very similar when the diesel price is "low", regardless of the cost of the electricity. Even if the prices are static during the whole ownership period, the sensitivity analysis on feeding provides with results of different situations that may occur in the near future.

Table 7. Scenario analysis based on the purchasing prices of electric and diesel vans

\begin{tabular}{|l|c|c|c|c|}
\hline (Diesel \& Electricity prices) & Scenario I & Scenario II & Scenario III & Scenario IV \\
\hline Electricity & High & High & Low & Low \\
\hline Diesel & High & Low & Low & High \\
\hline
\end{tabular}

Table 8. TCO in diesel and electricity prices scenarios I, II, III and IV

\begin{tabular}{|c|c|c|c|c|c|c|c|c|}
\hline TCO $[€]$ & \multicolumn{2}{|c|}{ Scenario I } & \multicolumn{2}{|c|}{ Scenario II } & \multicolumn{2}{|c|}{ Scenario III } & \multicolumn{2}{|c|}{ Scenario IV } \\
\hline & Road T. & No Road T. & Road T. & No Road T. & Road T. & No Road T. & Road T. & No Road T. \\
\hline Electric Van & \multicolumn{2}{|c|}{45,940} & \multicolumn{2}{|c|}{45,940} & \multicolumn{2}{|c|}{44,276} & \multicolumn{2}{|c|}{44,276} \\
\hline Diesel Van & 55,071 & 49,006 & 49,351 & 43,286 & 49,351 & 43,286 & 55,071 & 49,006 \\
\hline
\end{tabular}

\section{Conclusions}

This study investigated the competitiveness of EVs compared to ICEVs considering both the economic and the environmental perspectives. The analysis was conducted considering an Italian city (Milan). However, the sensitivity analyses can be extended to other contexts. The use of EVs for last mile deliveries proved to be economically feasible when an 8-year timeframe was considered. Even if the initial investment for EVs is high, owing to the fact that the purchasing price is nearly double when compared with ICEVs, the lower operating expenditures make EVs a competitive option. In particular, the breakeven point is approximately 4.5 years. In Milan, ICEVs are required to pay a road toll to enter the city center. This fee does not apply to EVs and contributes to making electric vans more beneficial than diesel ones. Without considering road toll, the competitiveness provided by EVs would decrease and the breakeven point would occur almost at the end of the ownership period. In this case, the performance of EVs and ICEVs becomes very similar from an economic perspective. However, if the environmental perspective is added, EVs prove to be the best choice. GHG emissions have been evaluated using the LCA method, and EVs turn out to be the best option in all the contexts considered. Specifically, the use of EVs leads to a reduction in GHG emissions by 17\% (in the $20 \mathrm{~km} /$ day case) to by $54 \%$ (in the $120 \mathrm{~km}$ /day case), or even more if a higher daily mileage is considered. Battery autonomy, in the analyzed contexts, does not represent a barrier to the employment of EVs.

However, the reliability of the results is strictly associated with the assumptions made during the application of the methodology. Moreover, only one van model of the light commercial vehicle-the electric one and its diesel counterpart—was considered. Thus, only data referring to the 2016 European electric van (e-NV200) were considered. Anyway, the scenario analysis on the purchasing price - stated that the characteristics and the performances of different vans are very similar, since they are all devoted to the B2C last mile delivery - provides an overview of prices range. Further, the total cost of ownership calculated for ICEVs can affect both energy and fuel price fluctuations. In this 
study, for the sake of simplicity, such factors were considered constant throughout the ownership period. Nevertheless, even though the analysis was conducted considering a particular city, Milan, where road toll is required and a specific mileage is set, the sensitivity analyses provide results on contexts with different numbers of kilometers travelled and without the payment of road toll.

This work is a valuable resource for both researches and practitioners. First, it contributes to the academic literature by investigating the competitiveness of EVs as substitutes for ICEVs for last mile deliveries. The economic evaluation is strengthened by an environmental analysis, which facilitates the consideration of both the perspectives. Furthermore, this work is useful for practitioners, both logistics operators and public entities. Logistics operators have a visibility on the opportunities - in terms of cost benefits and reduction of GHG emissions - that the employment of EVs can bring. Public entities can be provided with data that will prove useful in the definition of local regulations (e.g., encourage the adoption of EVs with fiscal or practical tangible benefits) and appropriate measures aimed at achieving environmental goals. 


\section{References}

Al-Alawi, B. M., \& Bradley, T. H. (2013). Total cost of ownership, payback, and consumer preference modeling of plug-in hybrid electric vehicles. Applied Energy, 103, 488-506.

Allen, J., Browne, M., \& Holguin-Veras, J. (2010). Sustainability strategies for city logistics. Green logistics: Improving the environmental sustainability of logistics, 282-305.

ARERA (2020). Andamento del prezzo dell'energia elettrica. Retrieved from [https://www.arera.it/it/dati/eep35.htm]

Breetz, H. L., \& Salon, D. (2018). Do electric vehicles need subsidies? Ownership costs for conventional, hybrid, and electric vehicles in 14 US cities. Energy Policy, 120, 238-249.

Browne, M., Allen, J., \& Leonardi, J. (2011). Evaluating the use of an urban consolidation centre and electric vehicles in central London. LATSS research, 35(1), 1-6.

Bubeck, S., Tomaschek, J., Fahl, U., 2016. Perspectives of electric mobility: total cost of ownership of electric vehicles in Germany. Transp. Policy 50, 63-77.

Cairns, S. (2005). Delivering supermarket shopping: more or less traffic?. Transport Reviews, 25(1), 51-84.

Cox, B., Bauer, C., Beltran, A. M., van Vuuren, D. P., \& Mutel, C. L. (2020). Life cycle environmental and cost comparison of current and future passenger cars under different energy scenarios. Applied Energy, 269, 115021.

Crainic, T. G., Ricciardi, N., \& Storchi, G. (2004). Advanced freight transportation systems for congested urban areas. Transportation Research Part C: Emerging Technologies, 12(2), 119-137.

Danielis, R., Giansoldati, M., \& Rotaris, L. (2018). A probabilistic total cost of ownership model to evaluate the current and future prospects of electric cars uptake in Italy. Energy Policy, 119, 268-281.

de Souza, L. L. P., Lora, E. E. S., Palacio, J. C. E., Rocha, M. H., Renó, M. L. G., \& Venturini, O. J. (2018).

Comparative environmental life cycle assessment of conventional vehicles with different fuel options, plug-in hybrid and electric vehicles for a sustainable transportation system in Brazil. Journal of Cleaner Production, 203, 444-468.

European Commission, 2011. White Paper: Roadmap to a Single European Transport Area - Towards a Competitive and Resource Efficient Transport System.

Feng, W., \& Figliozzi, M. A. (2012). Conventional vs electric commercial vehicle fleets: A case study of economic and technological factors affecting the competitiveness of electric commercial vehicles in the USA. Procedia-Social and Behavioral Sciences, 39, 702-711.

Fulton, K., \& Lee, S. E. (2013). Assessing sustainable initiatives of apparel retailers on the internet. Journal of Fashion Marketing and Management: An International Journal, 17(3), 353-366.

Hagman, J., Ritzén, S., Stier, J. J., \& Susilo, Y. (2016). Total cost of ownership and its potential implications for battery electric vehicle diffusion. Research in Transportation Business \& Management, 18, 11-17.

Jenn, A., Springel, K., \& Gopal, A. R. (2018). Effectiveness of electric vehicle incentives in the United States. Energy Policy, 119, 349-356.

Langbroek, J. H., Franklin, J. P., \& Susilo, Y. O. (2016). The effect of policy incentives on electric vehicle adoption. Energy Policy, 94, 94-103.

Lebeau, P., Macharis, C., Van Mierlo, J., \& Lebeau, K. (2015). Electrifying light commercial vehicles for city logistics? A total cost of ownership analysis. European Journal of Transport \& Infrastructure Research, 15(4).

Lebeau, P., Macharis, C., \& Van Mierlo, J. (2019). How to Improve the Total Cost of Ownership of Electric Vehicles: An Analysis of the Light Commercial Vehicle Segment. World Electric Vehicle Journal, 10(4), 90.

Letmathe, P., \& Suares, M. (2017). A consumer-oriented total cost of ownership model for different vehicle types in Germany. Transportation Research Part D: Transport and Environment, 57, 314-335.

Lévay, P. Z., Drossinos, Y., \& Thiel, C. (2017). The effect of fiscal incentives on market penetration of electric vehicles: A pairwise comparison of total cost of ownership. Energy Policy, 105, 524-533.

Lieb, R. (2008). The North American third-party logistics industry in 2007: the provider CEO perspective. Transportation Journal, 47(2), 39-53. 
Lieb, K. J., \& Lieb, R. C. (2010). Environmental sustainability in the third-party logistics (3PL) industry. International Journal of Physical Distribution \& Logistics Management, 40(7), 524-533.

Lin, C. Y., \& Ho, Y. H. (2008). An empirical study on logistics service providers' intention to adopt green innovations. Journal of technology management \& innovation, 3(1), 17-26.

Mangiaracina, R., Marchet, G., Perotti, S., \& Tumino, A. (2015). A review of the environmental implications of B2c e-commerce: a logistics perspective. International Journal of Physical Distribution \& Logistics Management, 45(6), 565-591.

Mills, G., \& MacGill, I. (2017). Assessing greenhouse gas emissions from electric vehicle operation in Australia using temporal vehicle charging and electricity emission characteristics. International Journal of Sustainable Transportation, 11(1), $20-30$.

Morrison, G., Stevens, J., \& Joseck, F. (2018). Relative economic competitiveness of light-duty battery electric and fuel cell electric vehicles. Transportation Research Part C: Emerging Technologies, 87, 183-196.

Osservatorio eCommerce B2c (2017). [Report]. L'e-commerce B2c in italia: Le prime evidenze per il 2018 [http://www.osservatori.net]

Osservatorio eCommerce B2c (2018). [Report]. Quanto vale l'e-commerce B2c in Italia [http://www.osservatori.net]

Palmer, K., Tate, J. E., Wadud, Z., \& Nellthorp, J. (2018). Total cost of ownership and market share for hybrid and electric vehicles in the UK, US and Japan. Applied energy, 209, 108-119.

Pieralice E \& Trepiedi L. (2016). E-Commerce e nuovi servizi per la logistica di ultimo miglio. Quali politiche delle citta’?, XVIII Riunione scientifica della società Italiana di economia dei trasporti e della logistica, Genova.

Quak, H. (2011). Urban freight transport: the challenge of sustainability. City distribution and urban freight transport: Multiple perspectives, 37-55.

Quak, H., Nesterova, N., van Rooijen, T., \& Dong, Y. (2016). Zero emission city logistics: current practices in freight electromobility and feasibility in the near future. Transportation Research Procedia, 14, 1506-1515.

Rafique, S., \& Town, G. E. (2019). Potential for electric vehicle adoption in Australia. International Journal of Sustainable Transportation, 13(4), 245-254.

Schöder, D., Ding, F., \& Campos, J. K. (2016). The impact of e-commerce development on urban logistics sustainability. Open Journal of Social Sciences, 4(03), 1.

Sierzchula, W. (2014). Factors influencing fleet manager adoption of electric vehicles. Transportation Research Part D: Transport and Environment, 31, 126-134.

Thiel, C., Perujo, A., \& Mercier, A. (2010). Cost and CO2 aspects of future vehicle options in Europe under new energy policy scenarios. Energy policy, 38(11), 7142-7151.

Topal, O., \& Nakir, İ. (2018). Total cost of ownership based economic analysis of diesel, CNG and electric bus concepts for the public transport in Istanbul City. Energies, 11(9), 2369.

Van Mierlo, J., \& Maggetto, G. (2007). Fuel cell or battery: Electric cars are the future. Fuel Cells, 7(2), 165-173.

Wu, G., Inderbitzin, A., \& Bening, C. (2015). Total cost of ownership of electric vehicles compared to conventional vehicles: A probabilistic analysis and projection across market segments. Energy Policy, 80, 196-214.

Wu, Z., Wang, M., Zheng, J., Sun, X., Zhao, M., \& Wang, X. (2018). Life cycle greenhouse gas emission reduction potential of battery electric vehicle. Journal of Cleaner Production, 190, 462-470.

Yu, A., Wei, Y., Chen, W., Peng, N., \& Peng, L. (2018). Life cycle environmental impacts and carbon emissions: A case study of electric and gasoline vehicles in China. Transportation Research Part D: Transport and Environment, 65, 409420.

Zachariadis, T. (2006). On the baseline evolution of automobile fuel economy in Europe. Energy Policy, 34(14), 17731785.

Zhang, S., Wu, Y., Liu, H., Huang, R., Yang, L., Li, Z., ... \& Hao, J. (2014). Real-world fuel consumption and CO2 emissions of urban public buses in Beijing. Applied Energy, 113, 1645-1655. 